\title{
Ensino do handebol em longo prazo: estudo a partir da opinião de treinadores
}

\author{
Rafael Pombo Menezes \\ Universidade de São Paulo (USP), Escola de Educação Física e \\ Esporte de Ribeirão Preto (EEFERP), Ribeirão Preto-SP, Brasil. \\ rafaelpombo@usp.br
}

Cita sugerida: Pombo Menezes, R. (2018). Ensino do handebol em longo prazo: estudo a partir da opinião de treinadores. Educación Física y Ciencia, 20 (2), e048. https://doi.org/10.24215/1514-0105e048

Recibido: 16 enero 2018 - Aceptado: 28 febrero 2018 - Publicado: 27 abril 2018

(c) (i)(2) Esta obra está bajo licencia Creative Commons Atribución-NoComercial-CompartirIgual 4.0 Internacional

(c) 


\section{Ensino do handebol em longo prazo: estudo a partir da opinião de treinadores}

Long-term Handball Teaching: a study of the coaches' speeches

Rafael Pombo Menezes

Universidade de São Paulo, Brasil

rafaelpombo@usp.br

\section{Resumo:}

O objetivo deste estudo foi investigar a preferência/utilização dos métodos de ensino por treinadores de handebol em quatro categorias (sub-12, sub-14, sub-16 e sub-18). Para isso foi elaborado um instrumento de entrevista semiestruturada e aplicado a treinadores do Estado de São Paulo. O Discurso do Sujeito Coletivo foi o método adotado para a tabulação e análise dos discursos, o que permitiu explorar as ideias centrais também em termos quantitativos. Os resultados apontaram particularidades entre as opiniões dos treinadores quando comparadas a alguns modelos descritos na literatura. Destaca-se, especialmente, a presença do método analítico-sintético na categoria sub-12, a presença do método global-funcional em todas as categorias e a crescente preferência/utilização referente ao método situacional. Conclui-se que os resultados apontaram características específicas a um grupo de treinadores do Estado de São Paulo, revelando um importante campo de investigação no âmbito do ensino do handebol. PalaVras-Chave: Ensino, Treinadores, Formação esportiva, Handebol.

\section{Abstract:}

The aim of this work was to investigate the preference/use of teaching approaches of handball coaches in four teams (under-12, under-14, under-16 and under-18). Six coaches of Sao Paulo State were interviewed (semistructured instrument). The method of Collective Subject Discourse was adopted for speech analysis, which allowed us to explore the central ideas (qualitative analysis). The results pointed out particularities among the coaches' opinions when comparing with some models proposed. It is noteworthy the presence of the traditional approach in under- 12 teams, the presence of the global-functional method (teaching through games) in all teams and a growing preference/use regarding the situational method. It was concluded that the results showed specific characteristics of a group of coaches from the State of Sao Paulo, which revealed an important research field related to handball teaching.

KEYWORDS: Teaching, Coaching, Sport formation, Handball.

\section{INTRODUÇÃO}

O ensino dos esportes em longo prazo é um tema que suscita o interesse de pesquisadores de diferentes áreas do conhecimento, em específico na tentativa de estabelecer modelos que apresentem etapas referentes à carreira esportiva (Côtè, Baker, \& Abernethy, 2007; Greco, Silva, \& Greco, 2012; Stambulova, Alfermann, Statler, \& Côtè, 2009). Stambulova et al. (2009) apontam que os modelos de carreira esportiva são definidos como uma sucessão de estágios (ou etapas) de envolvimento no esporte competitivo. Algumas das etapas apontadas pelos autores constituem-se na iniciação, desenvolvimento, aperfeiçoamento, manutenção e descontinuidade da prática esportiva.

Ao longo dessas etapas diferentes elementos são apresentados aos esportistas contemplando uma variedade de esportes nos momentos iniciais (visando ao maior envolvimento possível dos praticantes) e, na medida em que tais etapas vão se consolidando, há um grau maior de especialização em um desses, com exigências cada vez maiores de parâmetros como eficiência e eficácia.

Côtè et al. (2007) apresentaram o modelo de desenvolvimento e participação esportiva (DMSP) que contempla a formação esportiva em três diferentes carreiras: participação recreativa a partir de práticas variadas, desempenho de elite a partir de práticas variadas e desempenho de elite a partir da especialização precoce. Os autores apontam que no início do processo de formação dos atletas deve-se destinar grande 
parte do tempo com o jogo deliberado (experiências intrinsecamente motivantes, com gratificação imediata, que proporcionam divertimento aos praticantes) e, na medida em que se encaminha para o processo de especialização esportiva, atribui-se maior relevância à prática deliberada (atividades específicas de treino, com o intuito de melhoria do desempenho e recompensas imediatas).

Dois modelos foram identificados considerando o cenário específico do handebol. O primeiro deles é apresentado por Ehret, Späte, Schubert, \& Roth (2002) e estrutura-se a partir do oferecimento de práticas variadas até a categoria sub-14, com o processo de especialização iniciando na categoria sub-16, sem necessariamente especializar o jogador em um posto. Esse modelo é pautado na formação em longo prazo e preconiza que o jogador deva saber jogar em dois ou mais postos específicos mesmo na etapa de especialização. O segundo modelo, denominado "Sistema de formação e treinamento esportivo no handebol brasileiro (SFTE-HB)" centra-se na ideia de uma formação inicial generalista até a etapa de especialização (Greco et al., 2012). Os autores sugerem o desenvolvimento de diferentes capacidades dos jogadores (ao longo do tempo) a partir do ensino por meio de jogos, de situações de jogo e de exercícios coordenativos.

Esses modelos supõem que em cada etapa do processo de formação do jogador de handebol podem ser utilizados diferentes métodos de ensino, preconizando o desenvolvimento de diferentes capacidades. Dentre os métodos de ensino dos esportes coletivos, destacam-se três (Menezes, Marques, \& Nunomura, 2014): o método analítico-sintético (também conhecido como tecnicista, propõe o ensino a partir da fragmentação do jogo em elementos técnicos), o método global-funcional (ensino por meio de jogos) e o método situacional (pautado no ensino a partir de situações de jogo).

Por outro lado, os estudos que envolvem treinadores esportivos podem revelar importantes informações sobre o contexto no qual se dá o processo de formação esportiva, atentando-se para os aspectos inerentes à preferência/utilização dos métodos de ensino supracitados. Seria possível, assim, estabelecer comparações entre as decisões tomadas pelos treinadores e os modelos preconizados pelos diferentes autores.

Nesse cenário, as perguntas motivadoras para este estudo foram: "quais são os métodos de ensino preferidos/utilizados pelos treinadores em diferentes categorias?"; e "a partir da opinião dos treinadores, como se dá a distribuição desses métodos ao longo do tempo?”. Assim sendo, o objetivo desta pesquisa foi identificar e discutir, ao longo da formação do jogador de handebol, como se dá a distribuição dos métodos de ensino a partir da opinião dos treinadores.

\section{MÉTODO}

Participaram desta pesquisa seis treinadores de handebol do Estado de São Paulo, com média de idade de $42,7( \pm 6,4)$ anos, com tempo médio de experiência como treinador de $18( \pm 5,9)$ anos e como treinador das categorias de formação de 15,3 ( $\pm 4,8)$ anos. Os critérios de inclusão foram: a) ter classificado a equipe entre as três primeiras colocadas na la ou na 2a divisão dos Jogos Abertos do Estado (quando da entrevista), na categoria adulta feminina; b) ter sido (ou ainda ser) treinador ou assistente em todas as equipes das categorias de formação (sub-12, sub-14, sub-16 e sub-18). De um universo de seis treinadores possíveis, todos concordaram em participar da pesquisa, os quais assinaram um Termo de Consentimento Livre e Esclarecido aprovado previamente por um Comitê de Ética em Pesquisa institucional.

A opção pela pesquisa qualitativa justificou-se pela necessidade de identificar, descrever, analisar e interpretar aspectos referentes à complexidade do comportamento humano (Marconi \& Lakatos, 2011), em específico sobre a preferência/utilização dos métodos de ensino pelos treinadores em cada categoria. Pressupõe-se que esses podem apresentar diferentes opiniões sobre o tema, cuja construção do conhecimento pauta-se em experiências profissionais e/ou acadêmicas, porém tais opiniões são repletas de significados e representações que podem ser manifestados a partir de discursos-síntese que agregam opiniões semelhantes (Lefèvre \& Lefèvre, 2012). 
Esta pesquisa de caráter qualitativo teve como instrumento de produção dos dados a entrevista semiestruturada, devido à liberdade do entrevistador para explorar amplamente as questões (Marconi \& Lakatos, 2011). Côtè, Ericsson, \& Law (2005) apontam que quando os indivíduos (no caso desses, atletas) respondem perguntas pautando-se nas experiências vivenciadas, esses são mais confiáveis do que quando precisam de deduções e reconstrução de respostas a diversas questões gerais. Entende-se, aqui, que a mesma prerrogativa possa ser estendida aos treinadores.

As questões norteadoras da entrevista, que são parte de um instrumento mais amplo de pesquisa, foram: a) "Como você ensina os conteúdos na categoria __ ?"; b) "Como você acha que devem ser as atividades/ exercícios na categoria __ ?”; c) "Pode citar um exemplo que enfatize os passes?”. Nas questões a e b foram indagadas as diferentes categorias, separadamente, permitindo explorar seus contextos específicos. $\mathrm{Na}$ questão c foi selecionado o passe como exemplo por se tratar de um elemento básico do jogo, o que possibilitou investigar se havia inconsistências entre os métodos citados e os exemplos apontados.

Após a transcrição das entrevistas os depoimentos foram tabulados e analisados a partir do método do Discurso do Sujeito Coletivo (DSC) (Lefevre \& Lefevre, 2012). O método possibilitou expressar o pensamento dessa coletividade a partir da agregação de trechos dos discursos individuais referentes às opiniões sobre um determinado assunto (Lefevre \& Lefevre, 2003), neste caso o ensino do handebol.

Foram identificadas três figuras metodológicas: expressões chave (ECH: trechos literais contínuos e/ou descontínuos sobre uma dada temática, que possibilitam verificar a essência dos discursos); ideias centrais (IC: descrição sucinta e fidedigna do sentido dos discursos, revelam a essência desses); e o discurso do sujeito coletivo (DSC: discurso-síntese redigido em primeira pessoa, que agrega as opiniões manifestadas nas ECH com mesma IC) (Lefèvre \& Lefèvre, 2003).

A elaboração das IC possibilitou a identificação da frequência com a qual os métodos de ensino foram mencionados pelos treinadores quando se referiram às diferentes categorias (sub-12, sub-14, sub-16 e sub-18), bem como os motivos pelos quais optam por cada método (com trechos apresentados ao longo da seção de "Resultados e Discussão"). A partir dos métodos de ensino mencionados em cada categoria foi possível calcular o percentual de preferência/utilização por esses ao longo do tempo. Cabe destacar que tal análise não se refere ao tempo dedicado a cada método, mas ao fato de ter sido mencionado em cada categoria.

\section{RESULTADOS E DISCUSSÃO}

A partir dos discursos foi possível identificar a presença de três métodos de ensino: tradicional (analíticosintético), global (por meio de jogos) e situacional (pautado em situações extraídas do contexto do jogo), cuja preferência apresenta-se distribuída diferentemente ao longo do tempo. No Quadro 1 são apresentados os treinadores que mencionaram cada método nas diferentes categorias, bem como a frequência de opiniões para cada uma dessas. 


\begin{tabular}{|c|c|c|}
\hline Categoria & Métodos / treinadores & $\begin{array}{l}\text { Frequência de } \\
\text { opinióes }\end{array}$ \\
\hline Sub-12 & $\begin{array}{l}\text { - Analítico: S3 } \\
\text { - Global: S1, S2, S4, S5, S6 }\end{array}$ & 6 \\
\hline Sub-14 & $\begin{array}{ll}\text { - } & \text { Analítico: S1, S3, S4 } \\
\text { - } & \text { Global: S1, S2, S4, S5, S6 } \\
\text { - } & \text { Situacional: S1, S2 }\end{array}$ & 10 \\
\hline Sub-16 & $\begin{array}{ll}\text { - } & \text { Analítico: S1, S2, S4, S5, S6 } \\
\text { - } & \text { Global: S1, S2, S3, S4, S6 } \\
\text { - } & \text { Situacional: S1, S2, S3, S4, S5, S6 }\end{array}$ & 16 \\
\hline Sub-18 & $\begin{array}{ll}\text { - } & \text { Analítico: S1, S2, S3, S4, S5, S6 } \\
\text { - } & \text { Global: S1, S2, S4 } \\
\text { - } & \text { Situacional: S1, S2, S4, S5, S6 }\end{array}$ & 14 \\
\hline
\end{tabular}

\section{QUADRO 1}

Estratificação dos treinadores por categoria

Nota-se que o método global-funcional e o método analítico-sintético são mencionados por pelo menos um treinador em todas as categorias. Observa-se, ainda, que na categoria sub-16 é mencionada a preferência/ utilização de dois ou mais métodos por todos os treinadores, o que não se repete nas demais categorias. A categoria sub-18 apresenta um panorama semelhante ao da categoria sub-16, na qual o S3 menciona apenas um método.

A partir dos discursos dos treinadores referentes ao ensino em cada categoria foi possível identificar como se dá a distribuição da sua utilização ao longo do tempo. A partir da identificação das frequências das opiniões, foi calculado o percentual referente à preferência/utilização de cada método ao longo do tempo (Figura 1).

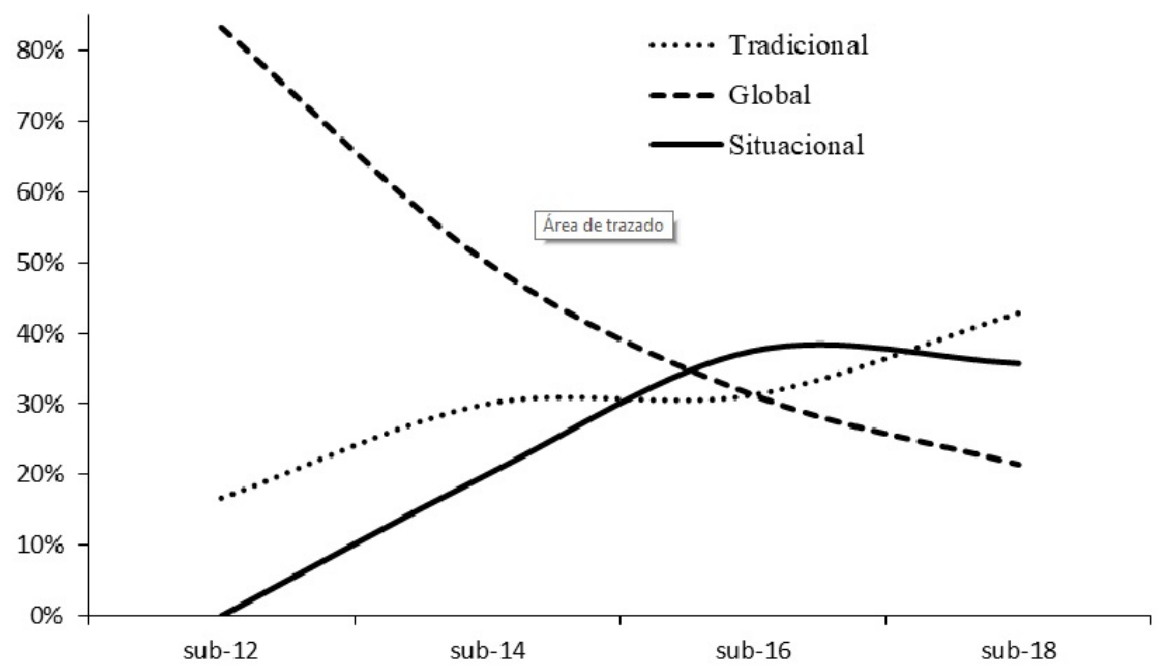

FIGURA 1

Percentual da preferência/utilização pelos métodos de ensino em cada categoria Dos autores

A partir dos dados apresentados no Quadro 1 e na Figura 1 é possível observar que ao longo do tempo há um comportamento variável em relação à preferência/utilização dos diferentes métodos de ensino. O método analítico-sintético é mencionado por um treinador na categoria sub-12 (Trecho 1), ao passo que apresenta 
um incremento ao longo das subsequentes. Esse aspecto indica que, na medida em que se aproxima de categorias como a sub-18 (ou etapa de especialização, na visão de Greco et al. (2012), esse método seja adotado com maior frequência, referindo-se basicamente ao aumento da eficácia e à busca por maior rendimento (conforme abordado no Trecho 2).

Trecho 1: O sub-12 é mais tecnicista, frente a frente; já posso começar a ensinar todos os tipos de passe, primeiro parado e depois em deslocamento ${ }^{\mathrm{S}}$.

Trecho 2: Tem que apurar a técnica ao máximo, trabalhar específico ${ }^{\mathrm{S5}, \mathrm{S} 6}$, é a idade [sub-18] que você pode tirar mais do jogador em questão técnica ${ }^{\mathrm{SG}}$; se todo o desenvolvimento anterior se foi bem trabalhado, ele vai estar com um conhecimento bom, uma parte motora muito boa ${ }^{\mathrm{S}}$. [...] Manteria o que é feito no sub-16, porém com um tempo maior de duração, tem que aperfeiçoar ${ }^{S 4, S 5}$, e pra aperfeiçoar você necessita de muita repetição ${ }^{S 5}$.

A crescente preferência pelo método analítico ao longo do tempo pode estar justamente relacionada com a necessidade que os treinadores sentem de aprimorar e refinar os gestos motores. Essa premissa vai ao encontro das perspectivas apontadas por Côtè et al. (2007) em relação ao maior investimento na especificidade do próprio esporte e a consequente exigência de resultados competitivos. Busca-se, então, o ensino da técnica pautando-se na repetição e automatização de movimentos e na fragmentação do jogo em unidades menores (Galatti \& Paes, 2007; Menezes et al., 2014). A repetição exaustiva de movimentos pode, ainda, ser desmotivante para o jogador e dificultar a compreensão da sua utilização no contexto do jogo (Galatti \& Paes, 2007; Menezes et al., 2014; Santana, 2005). Possivelmente por esses fatores, entre outros, diferentes autores (Côtè et al., 2007; Ehret et al., 2002; Greco et al., 2012) convergem as opiniões no sentido de oferecer práticas que sejam motivantes e, ao mesmo tempo, desafiem os jogadores a resolver problemas do jogo, com forte apelo à inteligência tática (Garganta, 1998).

Voltando às opiniões dos treinadores foi observado um comportamento semelhante ao do método analítico em se tratando da preferência/utilização do método situacional, o qual não é mencionado na categoria sub-12 e, na medida em que se aproxima da categoria sub-18, apresenta-se de maneira crescente. Esse aspecto também pode estar relacionado com a necessidade de especializar os jogadores (ao longo do tempo) de acordo com os postos específicos e, ainda, de buscar a consolidação de sistemas ofensivos, defensivos e condutas individuais pautando-se em contextos menores ao comparados com o jogo formal, que possibilitam aos jogadores identificar aspectos relevantes para a tomada de decisão (Trecho 3 ).

Trecho 3: Tudo é um recorte do jogo; mostrar as opções, e começar a trabalhar no sub-16 e no sub-18 aprimora, a parte de respostas ${ }^{54}$. Acho que o sub-18 é um aprimoramento, fazer o atleta entender que tem que dar resposta, que aquilo que ele pensou em fazer pode mudar e tem que dar uma resposta $^{S 4}$. As situações sempre vão me dar uma cara de trabalhar passe, arremesso, finta, já está embutido nessa ação o arremessar com pressão, o passar com pressão ${ }^{S 1}$.

Em direção diametralmente oposta às anteriores, o método global apresenta-se como a principal preferência/utilização nas categorias sub-12 e sub-14 e, após esta, inicia uma tendência descendente ao longo do tempo, principalmente a partir da categoria sub-16, na qual invertem-se as proporções entre os métodos. É importante ressaltar que a presença de métodos como o global e o situacional em diferentes categorias atende ao pressuposto de jogar, sem necessariamente dominar os elementos técnicos para então colocá-los "em jogo".

A diminuição da utilização do método global-funcional pode estar relacionada a dois aspectos. O primeiro se refere às regras do jogo na categoria sub-12, as quais apresentavam como requisitos às equipes (na época desta pesquisa) a obrigação da utilização do sistema defensivo individual, que se aproxima de muitos dos jogos utilizados para o ensino nessa. O segundo se refere às concepções e intenções dos treinadores sobre a utilização dos jogos como proposta de ensino, muitas vezes entendidos como sendo de caráter despretencioso ou somente recreativo (conforme trecho 4 - categoria sub-12 - e trecho 5 categoria sub-18). 
Trecho 4: No sub-12 é jogando, com brincadeiras e ludicidade ${ }^{S 1, S 2, S 4, S 5, S 6}[\ldots]$ porque o desenvolvimento da criança $[. .$. você tem que trabalhar no início não visando só o handebol ${ }^{\mathrm{S} 6}$.

Trecho 5: No sub-18 acho que tem sessão que você pode dar um prédesportivo pra um aquecimento ${ }^{S 2}$, o lúdico é só pra brincar, pra aquecer em alguns momentos; coloco os pequenos jogos como aquecimento ${ }^{\mathrm{S}}{ }^{\text {. }}$

Diferentemente da visão apontada no trecho 5, o jogo é considerado (no método global-funcional) o elemento fundamental, pelo qual as adaptações nas regras permitirão a abordagem de diferentes conteúdos, valorizando a lógica do próprio jogo com o jogador no centro do processo de ensino (Folle, Nascimento, \& Graça, 2015; Galatti \& Paes, 2007). Os estímulos são vistos como um conjunto organizado (e não fragmentado) (Greco, 2001), a partir de situações-problema baseadas em jogos de diferentes complexidades. Objetiva-se, portanto, uma mudança nos paradigmas de ensino ao comparado com o método analítico, buscando maior valorização de aspectos relacionados à tomada de decisão dos jogadores (Memmert \& Harvey, 2010). Por outro lado, os jogos e as situações de jogo podem apresentar grande volume de informações aos iniciantes, desfavorecendo a relação desses com a bola e, consequentemente, com seus companheiros (Santana, 2004). Por esse motivo enfatiza-se a necessidade de apresentar os jogos com complexidades crescentes e, ainda, com a perspectiva de mudar regras para que determinados comportamentos dos jogadores se manifestem com maior frequência.

Para Ehret et al. (2002), nas categorias sub-12 e sub-14 deve-se utilizar pequenos jogos, o que aponta para uma participação importante do método global-funcional. Cabe destacar que tal preocupação também é apontada por Greco et al. (2012) quando aludem ao grande espaço destinado ao que chamam de "jogos gerais" nessas categorias (com menor ênfase na sub-14), visando ao desenvolvimento da inteligência tática. De maneira análoga, Greco et al. (2012) destacam a importância dedicada ao método situacional na categoria sub-12, fator não observado nos treinadores entrevistados. Os autores ainda destacam a importância desse método na categoria sub-14, pelo fato de basear-se em unidades funcionais extraídas do jogo formal, mantendo as suas características. Deve-se buscar, portanto, ambientes que não priorizem a cobrança por resultados expressivos (excelência esportiva), em específico considerando-se uma perspectiva de curto prazo (não mencionado nos discursos dos treinadores).

Ehret et al. (2002) abordam que na categoria sub-14 deve-se utilizar um amplo repertório de técnicas específicas do handebol para a experimentação do movimento (e não com o caráter de especialização) e, em conjunto, deve-se evitar colocar os jogadores em postos específicos pré-definidos, visando à formação de jogadores polivalentes. Essa ideia apresenta-se como um forte argumento para a utilização do método global-funcional nessa categoria, uma vez que por meio dos jogos podem ser enfatizados diferentes elementos do handebol, bem como vai ao encontro da menção ao método situacional pela primeira vez, desde que considerada a vivência em diferentes postos específicos. Mesmo assim, chama-se atenção para a utilização/ preferência pelo método analítico-sintético na categoria sub-14, que pode ir de encontro a essa prerrogativa, se utilizado no sentido de especializar o movimento ou de criar um estereótipo considerado ideal para os postos específicos.

Embora autores como Côtè et al. (2007) apontem que ao longo do tempo haja maior preocupação com práticas que possibilitem o aumento do desempenho específico (principalmente nas etapas de especialização e investimento) ou, ainda, do aumento da eficácia (Greco et al., 2012), coloca-se como questão central a relação desta (eficácia) com o método analítico-sintético. Tal questão emerge do fato das decisões tomadas pelos jogadores ocorrerem em um contexto complexo de oposição e de cooperação, influenciado pelo número de jogadores e pelas ações desenvolvidas por esses. Para Santana (2005) quando a iniciação esportiva é pautada majoritariamente no desenvolvimento da técnica, pode haver priorização da competição como aspecto central da avaliação, levando à reprodução de um cenário do esporte profissional. Entende-se, portanto, que o ensino por meio de jogos valoriza a complexidade do fenômeno esportivo (Leonardo, Scaglia, \& Reverdito, 2009) e, assim, mesmo ensinando a jogar o handebol deve-se ensinar mais do que o handebol, corroborando os pilares apontados por Freire (1998). 
O modelo apresentado por Ehret et al. (2002) preconiza na categoria sub-12 a ênfase em uma base de desenvolvimento geral em detrimento dos conteúdos específicos do handebol (proporção aproximada de $75 \%$ e $25 \%$, respectivamente), na qual os jogadores devem jogar evitando o treinamento especializado. Nas categorias sub-14 e sub-16 há a tendência de equiparação dessas proporções, com prevalência da especificidade nas categorias sub-18 e sub-21. Os autores apontam que há a expectativa de uma formação multifacetada, inclusive com participação em diferentes esportes até a categoria sub-16, que terá como consequência uma carreira esportiva mais longa pelos praticantes. Os achados desta pesquisa, embora com diferentes ressalvas, aponta para uma direção semelhante, com aumento da especificidade e da complexidade do jogo ao longo das categorias.

De maneira semelhante, Côtè et al. (2007) apontam que duas das três possíveis trajetórias dentro do esporte apresentam como premissa o contato dos praticantes com diferentes esportes até, aproximadamente, 11-12 anos de idade (definida como idade de amostragem), tendo em vista o desenvolvimento do gosto pelo esporte. Tal concepção apresenta como ponto fundamental a compreensão da lógica de cada jogo, como uma importante prerrogativa para a transferência de conceitos entre esses (Galatti \& Paes, 2007; Gréhaigne \& Godbout, 1995), principalmente no que tange à percepção do espaço e à tomada de decisão em contexto específico.

No método analítico-sintético considera-se o ensino dos fundamentos de forma repetitiva e descontextualizada do jogo, priorizando o "como fazer" em detrimento do "quando fazer", "porque fazer" e "onde fazer" (Menezes et al., 2014). Assim, acredita-se que a aprendizagem da técnica seja um pré-requisito para acessar o jogo formal, premissa refutada pelo método global-funcional, o qual preconiza-se os fatos de "aprender jogando" e "jogar para aprender".

Nos resultados desta pesquisa nota-se que há a preocupação dos treinadores em manter os jogadores em contato com a lógica do jogo ao longo de diferentes categorias, seja pelo ensino por meio de jogos ou por meio de situações desses. A preferência pelo método global até a categoria sub-14 indica a presença do jogo no cotidiano do treinamento das equipes, assim como a necessidade relatada pelos treinadores de manter a prática de outros esportes, corroborando autores como Ehret et al. (2002) e Côtè et al. (2007).

Por outro lado, os achados desta pesquisa avançam no sentido de identificar preferências pelo método analítico desde as categorias iniciais, que vai de encontro à opinião de autores como Ehret et al. (2002) e Greco et al. (2012). Em especial na categoria sub-14 os treinadores mencionam a opção pelo método analíticosintético, indicando a preocupação com o início do desenvolvimento dos aspectos técnicos.

A categoria sub-16 apresentou resultados equilibrados sobre a utilização dos métodos de ensino pelos treinadores, sobretudo por indicarem a opção por dois ou três métodos (Trechos 6,7 e 8).

Trecho 6: No sub-16 [...] é aquela pedrinha que tem que ser polida mesmo, então a tendência de entrar aquela situação tecnicista com exercícios mais analíticos ${ }^{\mathrm{S} 1, \mathrm{~S} 2, \mathrm{~S} 5}$; vamos treinar um pouco isolado, treina pouco pro jogador não perder o interesse e fazer o jogo que é importante ${ }^{\mathrm{SS}}$.

Trecho 7: O jogo [...] vem enriquecer bastante quando [...] você começa a perceber que alguns ali ainda têm muita dificuldade, [...] passa a ser uma ferramenta até de você conseguir pegar esse pessoal que teve uma dificuldade nesse desenvolvimento, [...] porque não vai chegar todo mundo com a mesma leitura ${ }^{\mathrm{S} 2}$. 
Trecho 8: No sub-16 [...] começa a ter um pouco mais de [...] situações de jogo ${ }^{S 2},[. .$.$] recorto o jogo e chego naquela situação onde eu preciso$ fazer um passe ${ }^{\mathrm{S}}$. Pode trabalhar a relação de profundidade ${ }^{\mathrm{S} 2}$, fazer um trabalhinho de $1 \times 1,2 \times 2$, pra começar nesse progressivo, e começa a colocar $3 \times 3^{\mathrm{S} 2, \mathrm{~S} 3, \mathrm{~S} 5, \mathrm{~S} 6}, 4 \times 4^{\mathrm{S} 3, \mathrm{~S} 4, \mathrm{~S} 5}$.

Embora reconheçam a importância do método global-funcional (Trecho 7), a preocupação com a utilização do método analítico-sintético na/a partir da categoria sub-16 justifica-se pelo aumento da exigência pelo desempenho (cobrança por resultados), bem como a tentativa de aumentar a eficácia dos jogadores (Trecho 6). Para Greco et al. (2012) devem ser enfatizados os conceitos de eficiência e eficácia da técnica e adotar de maneira equilibrada o ensino incidental (relacionado ao método situacional) e intencional (relacionado ao método analítico-sintético ${ }^{1}$. A preferência pelo método situacional pode estar relacionada à especialização por postos específicos (que para Ehret et al., 2002, ocorre marcadamente nesta categoria, mas deve priorizar dois ou mais postos), assim como com o aprimoramento dos sistemas de jogo (ofensivos e defensivos), por abordar a especificidade dos cenários do jogo, mesmo que manifestados em unidades funcionais menores (Trecho 8 ).

Tais constatações revelam a complexidade inerente à categoria (ainda com questões regulamentares específicas, como a proibição de sistemas defensivos mistos), uma vez que pode marcar efetivamente o início do processo de especialização dos jogadores, o que Côtè et al. (2007) denominam "etapa de investimento". Folle et al. (2015) apontaram que na etapa de investimento os jogadores se comprometem e se dedicam, em linhas gerais, de maneira exclusiva a um esporte, além de participarem de competições mais expressivas.

Santos \& Menezes (2015) observaram em entrevistas com treinadores de handebol a opção de especializar seus jogadores preferencialmente nas categorias sub-18 e sub-16. Os autores destacaram que antes da especialização os treinadores devem priorizar métodos de ensino que possibilitem desenvolver um comportamento tático flexível, como proposto por Garganta (1998), e a formação de jogadores que saibam jogar em diferentes postos específicos, corroborando Ehret et al. (2002) e Greco et al. (2012).

Ao comparar os resultados apresentados pelos autores (Santos \& Menezes, 2015) com achados desta pesquisa é possível observar, por tendências inversas (ao longo do tempo) quando comparado o método analítico-sintético (tendência crescente) com o método global-funcional (tendência decrescente), a preocupação com o caráter generalista até a categoria sub-16, momento no qual também é apresentado o maior percentual para o método situacional (também com tendência crescente ao longo do tempo) e, a partir dessa, há preferência/utilização dos métodos analítico-sintético e situacional.

Pelos fatores supracitados entende-se que a partir da categoria sub-16 (considerando o contexto estudado) as atividades desenvolvidas visam à excelência esportiva, e se caracterizam por serem mais intensas e especializadas, justificando a forte presença dos métodos analítico-sintético e situacional nos discursos dos treinadores e reforçando uma substituição gradativa do divertimento pelo comprometimento (Folle et al., 2015). 
Nesse sentido, a diminuição da preferência/utilização do método global-funcional pelos entrevistados mantém a importância do contexto complexo dos jogos, mesmo que utilizados apenas como aquecimento para as sessões de treinamento (como ocorre na categoria sub-18, abordado no Trecho 4).

Ehret et al. (2002) apontam que os elementos centrais para o ensino na categoria sub-18 residem no fato de aprender a jogar apoiado em jogos básicos e com o apoio dos complementos analíticos. A diferença entre as preferências ao longo do tempo pode estar associada diretamente à necessidade de especialização dentro do contexto do handebol. Outro aspecto importante a ser destacado se refere ao aumento gradual da cobrança por resultados ao longo das categorias. Dessa forma, a efetividade exigida pelos treinadores pode justificar a preferência/utilização pelo método analítico-sintético nas categorias sub-16 e sub-18.

A variabilidade de estímulos sugerida por alguns autores e pela maioria dos entrevistados nesta pesquisa se deram, de forma geral, com o intuito de minimizar os efeitos negativos de uma possível especialização esportiva precoce. Concorda-se, ainda, com o fato de que o "jogo caracteriza-se como um sistema complexo, cujas partes não podem ser compreendidas sem a complementaridade entre elas, formando o 'todo' do jogo" (Leonardo et al., 2009, p.239), o que contempla/reforça a lógica interna do handebol.

Entende-se que mesmo durante a etapa de especialização sejam proporcionados aos jogadores estímulos variados, pautados em diferentes métodos de ensino (Menezes et al., 2014) e que, considerando um panorama de especialização em longo prazo, não necessariamente o método analítico-sintético será o mais utilizado para esse fim, principalmente pela desconexão com o cenário complexo do jogo. Menezes, Reis, \& Tourinho Filho (2015) apresentaram possibilidades para o ensino dos elementos técnico-táticos defensivos individuais do handebol nas categorias sub-14, sub-16 e sub-18. Os autores apontaram que os métodos de ensino ativos (como o global-funcional e o situacional) vêm ganhando espaço cada vez maior quando comparado ao método analítico-sintético, com destaque para o método situacional. Tal destaque se deu pelo fato de fornecer subsídios motores e cognitivos para que os defensores possam nortear seus processos de tomada de decisão.

A forte presença do método situacional nos resultados desta pesquisa, em especial na categoria sub-16, indica que a partir das diferentes possibilidades de relações numéricas (como o $1 \mathrm{x}$ goleiro) poderá ser enfatizada a eficiência dos elementos técnicos em associação com a sua adequação diante das ações do goleiro (eficácia). Ressalta-se, nesse sentido, que apenas o domínio técnico do jogador pode não garantir o acesso ao jogo de bom nível, principalmente pelo fato de o handebol ser um esporte dependente, sobretudo, da capacidade de tomada de decisão do jogador, dentro de um contexto dinâmico de cooperação e oposição.

Alguns dos resultados apresentados neste estudo diferem dos aspectos apresentados por diferentes autores, cujos principais destaques são: a presença do método analítico-sintético no início do processo de ensino; a marcante presença dos jogos ao longo de todas as categorias (pelas menções sobre o método global-funcional); o forte apelo ao método analítico-sintético nas categorias sub-14 e sub-16; a presença do método situacional na categoria sub-14. Cabe destaque, ainda, para a concordância com outros modelos sobre a diminuição da preferência/utilização do ensino por meio de jogos (método global-funcional) ao longo do tempo.

As particularidades aqui apresentadas podem promover debates mais aprofundados, na medida em que forem observados contextos mais amplos ou, ainda, buscar a caracterização de um panorama de ensino do handebol no Estado de São Paulo, extensível a outros contextos.

\section{CONSIDERAÇÕES FINAIS}

Diante do objetivo apresentado neste estudo foi possível identificar os métodos de ensino preferidos/ utilizados por um grupo de treinadores do Estado de São Paulo ao longo de quatro categorias (sub-12, sub-14, sub-16 e sub-18). Os resultados apontaram que há semelhanças e diferenças quando comparados com modelos propostos por diferentes autores. 
Destaca-se que os discursos dos treinadores apontaram, de maneira geral, uma formação inicialmente generalista, na qual os jogadores têm contato com diferentes elementos do jogo, com uma tendência para especialização iniciada na categoria sub-16. Observou-se, ainda, que há a presença de jogos nas sessões de treinamento de todas as categorias, o que remete à necessidade de contato constante com o contexto específico e complexo proporcionado por esses, independentemente de serem utilizados como elemento principal ou no momento do aquecimento.

Este estudo é sugestivo e, em nenhuma hipótese, buscou finalizar a discussão sobre a temática apresentada, identificando que são necessários mais estudos que possibilitem aprofundar na temática concernente à formação de jogadores de handebol no Brasil em longo prazo pela ótica dos treinadores. A partir dos resultados ora apresentados e discutidos será possível iniciar reflexões sobre o ensino do handebol em diferentes categorias, enriquecidas pelo fato de partir de um contexto prático.

Apresentaram-se como limitações deste estudo o fato de terem participado da entrevista um grupo de treinadores do Estado de São Paulo, o que pode tornar os dados não generalizáveis em um primeiro momento, principalmente pelo fato de não refletir o panorama do ensino em todo o Estado. A investigação foi centrada em treinadores de equipes femininas o que poderia, porventura, apresentar um contexto diferente das equipes masculinas.

Por outro lado, entende-se que o estudo permitiu identificar como tem sido concebida a preferência/ utilização referente aos diversos métodos de ensino ao longo do processo de formação do jogador, partindose de uma perspectiva apoiada na prática dos treinadores. Assim, a comparação com outros modelos estabelecidos a partir de outros cenários (internacionais, por exemplo), permitiu identificar que esses podem não responder suficientemente às questóes aqui investigadas (principalmente pela possibilidade de início tardio na prática do handebol, temática não abordada neste estudo).

Como perspectivas futuras de estudos, abre-se um fértil campo para a investigação em outros âmbitos (Nacional, Estaduais ou Municipais), na tentativa de compreender quais são as diferenças e as semelhanças entre as manifestações do handebol em diferentes cenários, com diferentes protagonistas.

\section{REFERÊNCIAS}

Côtè, J., Baker, J., \& Abernethy, B. (2007). Practice and play in the development of sport expertise. In R. Eklund \& G. Tenenbaum (Eds.), Handbook of sport psychology (pp. 184-202). Hoboken: Wiley.

Côtè, J., Ericsson, K. A., \& Law, M. P. (2005). Tracing the development of athletes using retrospective interview methods: a proposed interview and validation procedure for reported information. Journal of Applied Sport Psychology, 17, 1-19.

Ehret, A., Späte, D., Schubert, R., \& Roth, K. (2002). Manual de handebol: treinamento de base para crianças e adolescentes. São Paulo: Phorte Editora.

Folle, A., Nascimento, J. V., \& Graça, A. B. d. S. (2015). Processo de formação esportiva: da identificação ao desenvolvimento de talentos esportivos. Revista da Educação Física/UEM, 26(2), 317-329.

Freire, J. B. (1998). Pedagogia do futebol. Londrina: Midiograf.

Galatti, L. R., \& Paes, R. R. (2007). Pedagogia do esporte e a aplicação das teorias acerca dos jogos esportivos coletivos em escolas de esportes: o caso de um clube privado de Campinas-SP. Conexões, 5 (2), 31-44.

Garganta, J. (1998). Para uma teoria dos jogos desportivos colectivos. In A. Graça \& J. Oliveira (Eds.), O ensino dos jogos desportivos (3 ed., pp. 11-26). Porto: Universidade do Porto/Centro de Estudos dos Jogos Desportivos.

Greco, P. J. (2001). Métodos de ensino-aprendizagem-treinamento nos jogos esportivos coletivos. In E. Garcia \& K. Lemos (Eds.), Temas Atuais VI em Educação Fisica e Esportes (pp. 48-72). Belo Horizonte: Editora Health.

Greco, P. J., Silva, S. A., \& Greco, F. L. (2012). O sistema de formação e treinamento esportivo no handebol brasileiro (SFTE-HB). In P. J. Greco \& J. J. Fernández Romero (Eds.), Manual de handebol: da iniciação ao alto nível (pp. 
235-250). São Paulo: Phorte.

Gréhaigne, J.-F., \& Godbout, P. (1995). Tactical knowledge in team sports from a constructivist and cognitivist perspective. Quest, 47, 490-505.

Lefèvre, F., \& Lefère, A. M. C. (2003). Discurso do sujeito coletivo: um novo enfoque em pesquisa qualitativa (1 ed.). Caxias do Sul: EDUCS.

Lefevrre, F., \& Lefèvre, A. M. C. (2012). Pesquisa de representação social: um enfoque qualiquantitativo (2 ed.). Brasília: Liber Livro Editora.

Leonardo, L., Scaglia, A. J., \& Reverdito, R. S. (2009). O ensino dos esportes coletivos: metodologia pautada na família dos jogos. Motriz, 15 (2), 236-246.

Lima, C. O. V., Matias, C. J. A. d. S., \& Greco, P. J. (2012). O conhecimento tático produto de métodos de ensino combinados e aplicados em sequências inversas no voleibol. Revista Brasileira de Educação Física e Esporte, 26 (1), 129-147.

Marconi, M. d. A., \& Lakatos, E. M. (2011). Metodologia cientifica (6 ed.). São Paulo: Atlas.

Memmert, D., \& Harvey, S. (2010). Identification of non-specific tactical tasks in invasion games. Physical Education and Sport Pedagogy, 15 (3), 287-305.

Menezes, R. P., Marques, R. F. R., \& Nunomura, M. (2014). Especialização esportiva precoce e o ensino dos jogos coletivos de invasão. Movimento, 20 (1), 351-373.

Menezes, R. P., Reis, H. H. B. d., \& Tourinho Filho, H. (2015). Ensino-aprendizagem-treinamento dos elementos técnico-táticos defensivos individuais do handebol nas categorias infantil, cadete e juvenil. Movimento, 21 (1), 261-273.

Santana, W. C. (2005). Pedagogia do esporte na infância e complexidade. In R. R. Paes \& H. F. Balbino (Eds.), Pedagogia do esporte: contextos e perspectivas (pp. 1-24). Rio de Janeiro: Guanabara Koogan.

Santana, W. C. d. (2004). Futsal: apontamentos pedagógicos na iniciação e na especialização. Campinas: Autores Associados.

Santos, W. R., \& Menezes, R. P. (2015). A especialização esportiva de jogadores de linha e goleiros de handebol na visão de treinadores experientes. Paper presented at the Simpósio Internacional de Iniciação Científica da USP, Ribeirão Preto-SP.

Stambulova, N., Alfermann, D., Statler, T., \& Côtè, J. (2009). ISSP Position Stand: Career Development and Transitions of Athletes. International Journal of Sport and Exercise Psychology, 7 (4), 395-412.

\section{Notas}

1 As relações apontadas entre os métodos incidentais e intencionais com o situacional e o analítico, respectivamente, foram apresentadas por Lima, Matias, \& Greco (2012). 